\title{
Virtuelles Coaching für Führungskräfte in der Radiologie
}

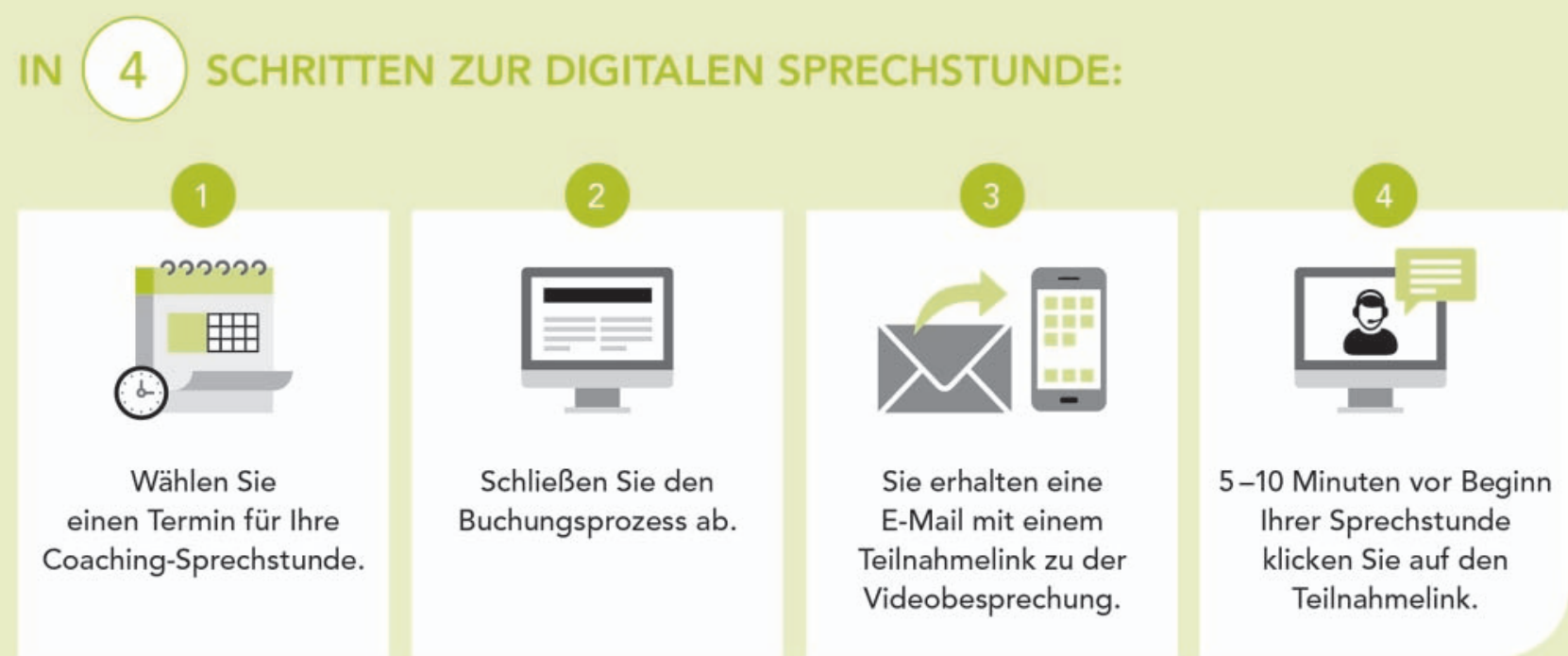

Um Führungsanforderungen auf die bestmögliche Weise gestalten zu können, greifen leitende Ärztinnen und Ärzte gerne auf externe Coaches mit ausgewiesener Expertise für medizinische Kontexte als erfahrene und kompetente Sparringspartner zurück. Ob bei der Lösung von Konfliktsituationen oder der strategischen Entwicklung der Abteilung - Coaches können gemeinsam mit ihren Klienten in vertrauensvollen Gesprächen Situationen analysieren und konkrete Umsetzungsschritte entwickeln. Coaching kann jedoch sehr zeit- und kostenintensiv sein. Manchmal lässt sich auch kurzfristig kein Termin für einen aktuellen Beratungsanlass finden. Eine effiziente und effektive Alternative stellt daher ein professionelles Coaching per Video dar.

Das Videocoaching der Röntgen Akademie bietet - ähnlich der ärztlichen Videosprechstunde, die seit Ende 2019 als abrechenbare GKV-Leistung anerkannt ist - eine individuelle, professionelle Beratung, die auch kurzfristig realisierbar ist und zudem auch Geld spart. Dabei profitieren insbesondere DRG-Mitglieder und Teilnehmende der Veranstaltungsreihe „Führungskompetenzen für Radiologen“ von Sonderkonditionen.
Ihre Vorteile auf einen Blick:

- Feedback und Entscheidungshilfe von unabhängiger und kompetenter Seite

- Wahrnehmung und Weiterentwicklung des persönlichen Verhaltensrepertoires

- Verbesserung der Führungskompetenzen

- Stärkung der eigenen Führungspersönlichkeit und Haltung

- Evaluation des Coachings

Ihr (virtueller) Coach für den medizinischen Kontext

Seit 2016 gestaltet Jens Hollmann unter dem Dach der Röntgen Akademie für Führungskräfte äußerst erfolgreich Seminare und Workshops speziell für angehende Führungskräfte, junge Chefärzte und Chefärztinnen sowie niedergelassene Ärztinnen und Ärzte in der Radiologie. Der ExecutiveCoach ist Inhaber des Unternehmens medplus-kompetenz ${ }^{\circledR}$ (medplus-kompetenz. de), lehrt seit über zehn Jahren in MBA-Studiengängen im deutschsprachigen In- und Ausland, berät seit mehr als 15 Jahren Chefärztinnen und Chefärzte und ist Autor zahlreicher Publikationen zum Thema.

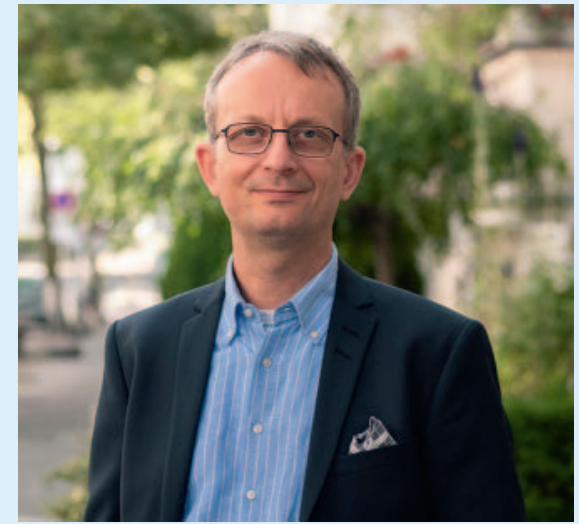

Jens Hollmann

Gebühren für eine Coaching-Sprechstunde:

- Teilnehmer Röntgen Akademie für Führungskräfte der DRG (290,- zzgl. $19 \%$ MwSt.)

1 Stunde@€345.00

- DRG-Mitglieder (320,- zzgl. 19\% MwSt.) 1 Stunde @€379.00

- Nichtmitglieder (350,--zzgl. 19\% MwSt.) 1 Stunde @€419.00

Interessiert? Dann hier gleich einen Termin für Ihre persönliche Videosprechstunde vereinbaren! www.drgakademie.de > Führungsakademie > Virtuelles Coaching 